\title{
Cutaneous small vessel vasculitis
}

INSERM

\section{Source}

INSERM. (1999). Orphanet: an online rare disease and orphan drug data base. Cutaneous small vessel vasculitis. ORPHA:889

Cutaneous leukocytoclastic ang iitis is a small-vessel vasculitis presenting with palpable purpura and urticarial lesions which predate the purpuric lesions most frequently observed on the legs. Systemic symptoms including fever, cough, hemoptysis, sinusitis, arthralgia, arthritis, myalgia, abdominal pain, diarrhea, hematochezia, paresthesia, weakness, and hematuria may be observed. Skin biopsy reveals exudates rich in neutrophils, endothelial damage, fibrin deposition, and leukocytoclasis in postcapillary venules of small vessels. Cutaneous leukocytoclastic ang iitis can be idiopathic (in up to $50 \%$ of cases) or secondary to infections, medications (such as antituberculosis medication), collagen vascular diseases, or neoplasms. 